\title{
Getting To Know, or Stepping Out in an Entirely Different Way · Akua Lezli Hope
}

for Swan

Still, it's how we negotiate

not that. style yet. rule

and measure deep the interface. just

Don't say the concrete alchemies night

like grassbreeze and palmetto sea

or sand-sting and dune-dance.

Where is your body wired? to

telegraph the moment.

coiled-lock conductors

spark fresh air, sear

space with pigment's trace and linen stretched

pinned flags on backyard line

tiered gravity defiers, signal clean

Massacre meaning's first blush

spread soil with this fleshy compost

and alter sacrificial curtsies to don

the bloodfruit's leather skin. Live.

July 1980 